\title{
Heterokaryosis in Fusarium oxysporum f.sp. lycopersici
}

\author{
By L. E. SANCHEZ,* J. V. LEARY AND R. M. ENDO \\ Department of Plant Pathology, University of California, Riverside, \\ California 92502, U.S.A.
}

(Received 17 March 1975; revised 8 October 1975)

\begin{abstract}
SUMMAR Y
Intra-isolate and inter-isolate heterokaryons were synthesized between auxotrophic mutants of Fusarium crown rot, 'purple variant' and the wilt isolates. This is the first report of intra- and inter-isolate heterokaryons in Fusarium oxysporum f.sp. lycopersici. Conidial ratios determined for several heterokaryons between different mutants of the Fusarium crown rot organism showed that the ratio is constant for each heterokaryon and that the ratio usually is in favour of one of the mutants.
\end{abstract}

\section{INTRODUCTION}

A new strain of Fusarium oxysporum (Schl.) f.sp. lycopersici (Sacc.) Snyder and Hansen which causes a generalized root and crown rot of susceptible tomato varieties has been identified and described by Leary \& Endo (197I). A characteristic of this race is the segregation of non-pathogenic 'purple variant' clones when the wild-type is propagated by single spore isolations. The mutagenesis and pathogenicity of these strains is the subject of a previous paper (Sanchez, Leary \& Endo, 1975).

The present investigation was designed to test the ability of nutritionally marked strains of the crown rot, wilt and 'purple variant' types to form intra- and inter-strain heterokaryons. Conidial ratios were also studied and attempts were made to alter these ratios by adjusting the nutritional conditions.

\section{METHODS}

Strains. For the origin and details of the wild-type strains and the procedures used to obtain the mutants, see Sanchez et al. (I975).

Heterokaryon formation. With one method, $5 \mathrm{~mm}$ agar plugs of two different auxotrophic mutants were placed $2.5 \mathrm{~cm}$ apart on a Schizophyllum minimal agar (SMA) (Raper \& Miles, I958) plate supplemented with $10 \mu \mathrm{mol}$ of the required growth factors $/ \mathrm{ml}$. Another technique employed was a modification of the method of Caten \& Jinks (I966). A 0. I ml drop of a spore suspension containing $0.5 \times 10^{5}$ spores of each mutant was placed in the centre of a SMA plate supplemented with $10 \mu \mathrm{mol}$ of the growth factors required by each of the mutants/ml.

Complementation tests for heterokaryons. Agar plugs I $\mathrm{mm}$ in diameter were transferred from the areas of abundant growth on the supplemented SMA to SMA and Schizophyllum migration complete agar (SCA) plates (Snider \& Raper, 1958), and growth of the presumed heterokaryons was compared.

Isolation of heterokaryotic hyphal tips and heterokaryotic mycelium fragments. The degree of complementation and the stability of the heterokaryon was assayed by the following

* Present address: Faculty of Agronomy, University of Chile, Santiago, Chile. 
procedures: (i) Single hyphal tip fragments I to $4 \mathrm{~mm}$ in length were cut from a heterokaryon growing on SMA and transferred to SMA and SMA supplemented with the individual growth factors. (ii) Complementing heterokaryons growing on SMA were blended in $25 \mathrm{ml}$ of Schizophyllum minimal broth (SMB) in a Waring blender for two periods of $30 \mathrm{~s}$ interrupted by a $15 \mathrm{~s}$ interval. A $5 \mathrm{ml}$ sample was pipetted into a $300 \mathrm{ml}$ Erlenmeyer flask containing $25 \mathrm{ml}$ of SMB and incubated at $25^{\circ} \mathrm{C}$ for four days until a compact mat of mycelium was formed. The mat was washed five times with sterile water to remove the spores. The mat of mycelium was then blended as described above, the concentration of fragments was adjusted to 30 to $40 / \mathrm{ml}$, and $\mathrm{r} \mathrm{ml}$ portions of the fragment suspension were pipetted into $2 \mathrm{ml}$ of molten $2 \%(\mathrm{w} / \mathrm{v})$ SMA. The entire $3 \mathrm{ml}$ suspension was overlaid on SMA, SCA, and on SMA plus each growth factor. These cultures were incubated at $25{ }^{\circ} \mathrm{C}$ and assayed for growth after $48 \mathrm{~h}$.

Determination of the conidial ratios of heterokaryons. Microconidia were harvested from complementing heterokaryons growing in SMA. Ten plugs, $5 \mathrm{~mm}$ in diameter, were taken at random, suspended in sterile water, agitated on a Vortex mixer and the spores separated by filtration through Whatman No. I filter paper. The spore concentration was adjusted to about $300 / \mathrm{ml}$ and $\mathrm{I} \mathrm{ml}$ samples were pipetted into $2 \mathrm{ml}$ of $2 \%(\mathrm{w} / \mathrm{v})$ molten SMA and overlaid on to SMA plates supplemented differentially with the growth factors required by the mutant components of the heterokaryon. The plates were incubated at $25^{\circ} \mathrm{C}$ and the colonies counted after $48 \mathrm{~h}$.

Cross-feeding experiments. The degree of cross-feeding between different pairs of mutants was determined by placing $5 \mathrm{~mm}$ plugs of each of the mutants $5 \mathrm{~cm}$ apart on SMA plates supplemented differentially with the growth factors required by the mutants. This was based on the assumption that only one mutant should grow normally throughout the plate, while the growth of the other mutant would not be stimulated unless cross-feeding occurred.

\section{RESULTS}

\section{Heterokaryon formation}

When combinations of mutants were made on minimal agar the conidia did not germinate and no significant mycelial growth from the agar plugs occurred under such conditions. No significant growth occurred when the medium was supplemented with less than Io $\mu \mathrm{mol}$ of any required nutrient $/ \mathrm{ml}$. This concentration was used routinely in subsequent experiments. When a drop of spores was placed on the centre of a plate of SMA supplemented as described above, presumptive heterokaryons were detected as tiny actively growing colonies (Fig. I $b$ ). The same visual indication was observed when two mutants were mated by placing agar plugs $2.5 \mathrm{~cm}$ apart on the supplemented SMA plate. Colonies which originated from complementation were easily detected in the area of interaction between the hyphae of the two mutants in the centre of the plate (Fig. I $a$ ). Such colonies were visible between Io and I 2 days after the plates were inoculated. Most of the auxotrophic mutants tested showed no growth which could be attributed to cross-feeding, and only a few gave a positive response after the supplemented mutant had grown extensively for several days (Fig. $2 b$ ).

Growth from I mm plugs of several of the presumed heterokaryons synthesized between several pairs of mutants of the Fusarium crown-rot wild-type isolate on SMA and SCA is summarized in Table I. Wide variation in the amount of growth among the different forced heterokaryons was observed. For example, when a mutant of the Fusarium crownrot wild-type isolate (CR) which required inositol and tryptophan (inos- $I$ trp-I) was combined with each of several other mutants, the amount of growth varied depending upon the 

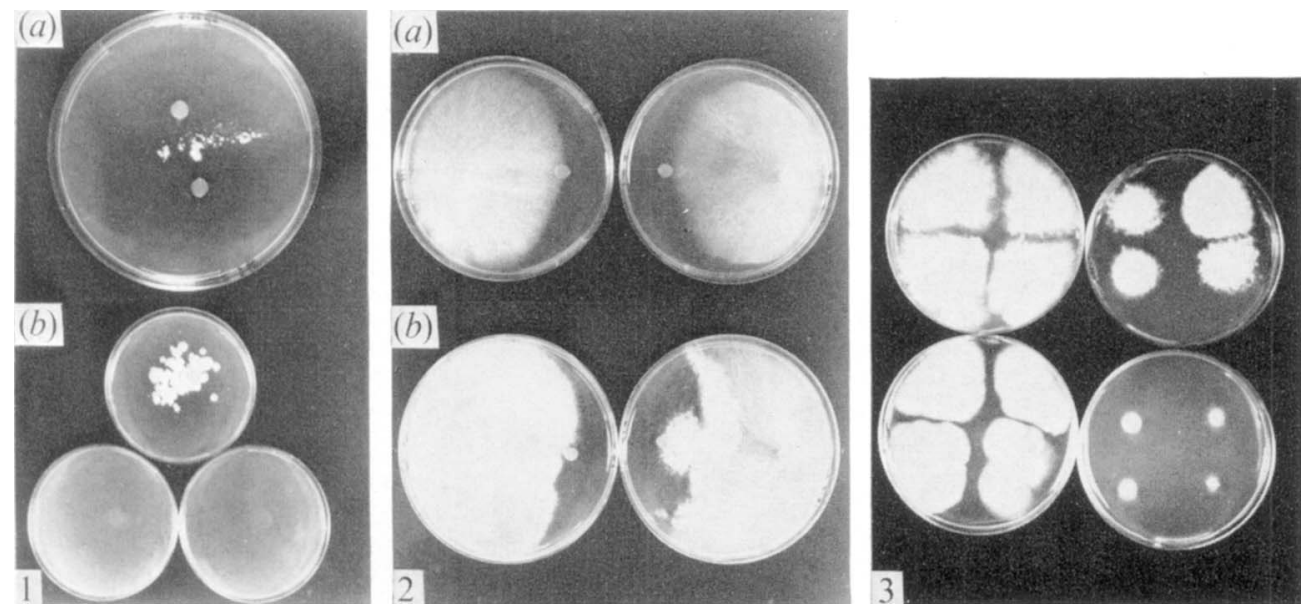

Fig. I. Techniques used to synthesize heterokaryons. (a) Plugs of two mutants were placed $2.5 \mathrm{~cm}$ apart on SMA plates supplemented with $10 \mu \mathrm{mol}$ of both growth factors $/ \mathrm{ml}$. Tiny visible colonies formed in the area of mycelial interaction represent the formation of heterokaryons. (b) A drop of a mixture of spore suspension of the mating mutants (top plate) was placed in the centre of a supplemented SMA plate (same as above). Small visible colonies around the drop represented the formation of heterokaryons. No visible growth was observed in either of the two lower plates containing the mutants inoculated alone. Plates were incubated for 12 days at $25{ }^{\circ} \mathrm{C}$.

Fig. 2. Cross-feeding tests. (a) Each plate was inoculated with both mutants (CR inos-I ade-I and W met-I) $5 \mathrm{~cm}$ apart. The plate on the left was supplemented with adenine and the plate on the right with methionine. (b) Each plate was inoculated with the mutants, CR inos-I met-I and CR inos-I $\arg -I$. The plate on the left was supplemented with methionine and the plate on the right with arginine. Plates were incubated for Io days at $25^{\circ} \mathrm{C}$. (All plates contained inositol.)

Fig. 3. Compatible and non-compatible heterokaryon formation. Above: Heterokaryons (CR inos- $I$ trp-I + CR inos-I leu-4) growing in SMA (right) and in SCA (left). Below: Mutants (CR inos-I $\operatorname{trp}-I+\mathrm{P}$ inos-I met-I) which did not form heterokaryons; the plate on the right is SMA and the plate on the left is SCA. Plates were incubated for 6 days at $25^{\circ} \mathrm{C}$.

other mutant. When heterokaryons were synthesized between three different argininerequiring mutants and CR inos-I nic-I the growth of the heterokaryon was different for each combination. Some heterokaryons, such as those formed between the CR inos-I arg-4+CR inos- $I$ trp-I and the CR inos- $I$ arg-4 + CR inos- $I$ leu-3 did not grow well when transferred from supplemented SMA to non-supplemented SMA (Fig. 3). Heterokaryons were formed between only a few of the mutants of the Fusarium wilt isolate (W), and those that did form had a reduced growth rate on SMA when compared with the growth on SCA (Table 2). Heterokaryons were formed between some pairs of mutants of CR and the Fusarium crown-rot 'purple variant' (PV). The growth of these heterokaryons on SMA supplemented with a low concentration of the required nutrients was good (Table 3), but when they were transferred to non-supplemented SMA the growth of the heterokaryons was significantly reduced. In the heterokaryons studied between the CR and PV isolates (Table 3), the nutritional requirements assorted exclusively with the parental phenotypes.

Only two successful heterokaryons were synthesized from the crosses between the several pairs of mutants of the $\mathrm{W}$ organism and CR (Table 3).

Combinations of mutants of the PV isolates and also those between mutants of the W isolates produced few heterokaryons, and their growth was generally poor. Heterokaryons were formed in crosses between a few pairs of mutants of the CR and the PV isolates. Since the 'purple variant' was obtained as a segregant from the CR isolate, we assumed that the 
Table I. Synthesis and growth of heterokaryons between double mutants of the Fusarium crown-rot wild-type isolate $(C R)$

\begin{tabular}{|c|c|c|}
\hline \multirow[b]{2}{*}{ Mutants* } & \multicolumn{2}{|c|}{ Heterokaryon formation } \\
\hline & $\begin{array}{c}\text { Synthesis on } \\
\text { supplemented } \\
\text { SMA } †\end{array}$ & $\begin{array}{c}\text { Growth after } \\
\text { transfer to } \\
\text { SMA } \$\end{array}$ \\
\hline $\mathrm{CR} \operatorname{trp}-I+\mathrm{CR} l e u-I$ & $+t+t$ & ++++ \\
\hline CR $\operatorname{trp}-I+\mathrm{CR}$ leu-4 & ++++ & $+++t$ \\
\hline CR $\operatorname{trp}-I+\mathrm{CR}$ arg-3 & $++t$ & ++ \\
\hline $\mathrm{CR}$ trp- $I+\mathrm{CR}$ arg- 4 & ++++ & + \\
\hline CR $\operatorname{trp}-1+\mathrm{CR}$ cys -2 & ++++ & ++ \\
\hline CR ade-I + CR leu-2 & $+++t$ & ++++ \\
\hline CR ade-I + CR leu-3 & $+++t$ & ++++ \\
\hline $\mathrm{CR}$ ade $-\mathrm{I}+\mathrm{CR}$ arg -3 & $+t+t$ & +++ \\
\hline $\mathrm{CR}$ ade $-I+\mathrm{CR}$ arg- 4 & $+t$ & + \\
\hline $\mathrm{CR}$ ade $-I+\mathrm{CR}$ trp-I & +++++ & +++ \\
\hline $\mathrm{CR}$ ade-I + CR nic-I & $+t+t$ & $+t+t+$ \\
\hline $\mathrm{CR}$ ade $-\mathrm{I}+\mathrm{CR}$ cys -2 & +++++ & ++++ \\
\hline $\mathrm{CR}$ cys $-\mathrm{I}+\mathrm{CR}$ leu-2 & $+++t+$ & $+++t$ \\
\hline CR nic-I + CR leu-3 & +++++ & ++++ \\
\hline $\mathrm{CR}$ nic-I + CR arg-2 & +++ & $+t+$ \\
\hline CR nic-I + CR leu-3 & $+t+t$ & $+t+t$ \\
\hline $\mathrm{CR}$ nic-I + CR trp-I & ++++ & +++ \\
\hline CR nic-I + CR arg-4 & +++ & + \\
\hline $\mathrm{CR}$ nic- $-\mathrm{C}+\mathrm{CR}$ arg-2 & $++t$ & $++t$ \\
\hline $\mathrm{CR}$ nic-I + CR arg-3 & $+++t$ & ++++ \\
\hline CR nic-I + CR cys -2 & $+t+t$ & ++++ \\
\hline CR leu-3 + CR arg-4 & $++t+$ & + \\
\hline
\end{tabular}

* All strains used required inositol (inos-I) in addition to the requirements listed.

$\dagger$ Minimal agar supplemented with $10 \mu \mathrm{mol} / \mathrm{ml}$ concentrations of the growth factors required by both mutants.

$\ddagger$ Growth of the heterokaryon - , no heterokaryon formed;,,,++++++++++ and +++++ , 10, I0 to 25,25 to 50,50 to 75 , and 75 to $100 \%$ growth, respectively, as compared with growth on SCA.

Table 2. Synthesis and growth of heterokaryons between single mutants of the Fusarium wilt isolate $(W)$

\begin{tabular}{|c|c|c|}
\hline \multirow[b]{2}{*}{ Mutants } & \multicolumn{2}{|c|}{ Heterokaryon formation } \\
\hline & $\begin{array}{l}\text { Synthesis on } \\
\text { supplemented } \\
\text { SMA* }\end{array}$ & $\begin{array}{c}\text { Growth after } \\
\text { transfer to } \\
\text { SMA } \dagger\end{array}$ \\
\hline $\mathrm{W}$ met-2 $+\mathrm{W}$ inos-I & + & + \\
\hline $\mathrm{W}$ met $-2+\mathrm{W}$ arg-3 & - & - \\
\hline $\mathrm{W}$ arg-3 $+\mathrm{W}$ inos $-I$ & + & - \\
\hline $\mathrm{W}$ arg-3 $+\mathrm{W}$ met -3 & - & - \\
\hline $\mathrm{W}$ arg-3 $+\mathrm{W} \operatorname{trp}-I$ & - & - \\
\hline $\mathrm{W} \arg -I+\mathrm{W} \operatorname{trp}-I$ & - & - \\
\hline $\mathrm{W}$ met-2 $+\mathrm{W}$ trp-I & ++ & + \\
\hline $\mathrm{W} m e t-3+\mathrm{W}$ trp-I & - & - \\
\hline $\mathrm{W}$ cys $-I+\mathrm{W} \operatorname{trp}-I$ & - & - \\
\hline $\mathrm{W}$ inos-I + W trp-I & - & - \\
\hline $\mathrm{W}$ inos-I $+\mathrm{W}$ arg-I & ++ & + \\
\hline $\mathrm{W}$ inos $-I+\mathrm{W}$ met -3 & - & - \\
\hline $\mathrm{W}$ inos $-I+\mathrm{W}$ cys $-I$ & - & - \\
\hline
\end{tabular}

* Minimal agar supplemented with Io $\mu \mathrm{mol} / \mathrm{ml}$ concentrations of the growth factors required by both mutants.

$\uparrow$ Growth of the heterokaryon (as in Table I). 
Table 3. Synthesis and growth of heterokaryons between mutants of the Fusarium crown-rot wild-type $(C R)$ and the 'purple variant' $(P V)$ isolates, and between mutants of the Fusarium crown-rot wild-type and Fusarium wilt isolates $(W)$

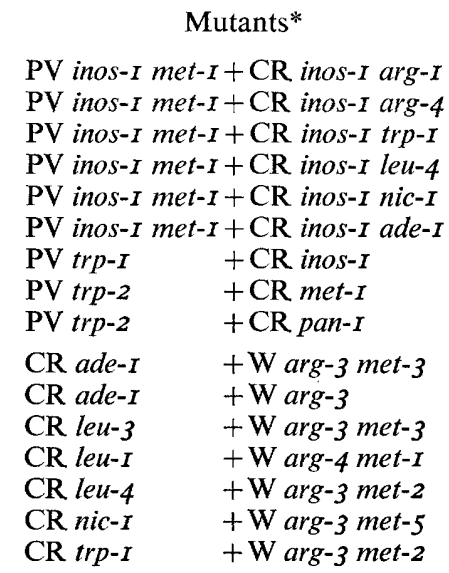

* Each of the CR double mutants required inositol (inos- $I$ ) in addition to the requirements listed.

$\uparrow$ Minimal agar supplemented with $10 \mu \mathrm{mol} / \mathrm{ml}$ concentrations of the growth factors required by the two mutants.

$\ddagger$ Growth of the heterokaryon (as in Table $\mathrm{I}$ ).

formation of heterokaryons between the two would occur readily. For unexplained reasons, this was not true. Heterokaryons were also synthesized in crosses between some mutants of the $\mathrm{CR}$ isolate and the $\mathrm{W}$ isolate.

\section{Conidial ratios and growth of several heterokaryons of the Fusarium crown-rot wild-type mutants}

Conidial ratios were determined for the CR inos-I leu-4+CR inos-I trp-I heterokaryons growing on supplemented SMA (Table 4). The spore ratio was several fold in favour of the tryptophan requirer over the leucine requirer, even though the heterokaryons were growing on SMA supplemented with leucine. These heterokaryons, when transferred to SMA, showed the same conidial ratios as reported in Table 4. Conidial ratios from other heterokaryons growing on SMA indicated that in the heterokaryons studied, one of the mutants predominated (Table 5). In the heterokaryon CR inos- I ade-I +CR inos- I leu-I, the leucine mutant (leu-I) predominated. However, when CR inos- $I$ ade-I was used in a cross with CR inos-I leu-4, the conidial ratio of the heterokaryon changed so that the adenine mutant predominated.

The different heterokaryons varied greatly in colony diameter after a fixed growth period. In heterokaryons formed between CR inos-I nic- $I$ and three other mutants, the growth of each heterokaryon was obvious upon macroscopic examination. 
Table 4. Conidial ratios of several heterokaryons of mutants of the Fusarium crown-rot wildtype isolate recovered from minimal agar supplemented with leucine

\begin{tabular}{|c|c|c|c|}
\hline $\begin{array}{c}\text { Heterokaryon } \\
\text { CR inos-I leu- } 4 \\
\quad+ \\
\text { CR inos-I trp-I }\end{array}$ & $\begin{array}{l}\text { No. of } \\
\text { colonies on } \\
\text { SMA plus } \\
\text { leucine* }\end{array}$ & $\begin{array}{l}\text { No. of } \\
\text { colonies on } \\
\text { SMA plus } \\
\text { trytophan* }\end{array}$ & $\begin{array}{l}\text { Conidial } \\
\text { ratio } \\
\text { leu/trp } \dagger\end{array}$ \\
\hline I & 117 & 415 & $\mathrm{I}: 4$ \\
\hline II & 73 & 250 & I $: 3$ \\
\hline III & 58 & 291 & I : 5 \\
\hline IV & 140 & 328 & I : 2 \\
\hline $\mathrm{V}$ & 26 & 125 & $1: 5$ \\
\hline
\end{tabular}

* Total number of colonies from five plates.

$\uparrow$ Spore ratio determined directly from the heterokaryons formed on SMA plus leucine.

Table 5. Conidial ratios and growth of several heterokaryons synthesized between mutants* of the Fusarium crown-rot wild-type isolate

Heterokaryon

CR ade-I + CR nic-I
CR ade-I + CR leu-I
CR ade-I + CR leu-4
CR ade-I + CR arg-I
CR trp-I + CR nic-I
CR leu-4 + CR nic-I
CR leu-4 + CR trp-I
Conidial ratio $\dagger$ Colony diameter $(\%) \ddagger$

$\begin{array}{ll}\text { I }: 1 & 84 \cdot 0 \\ 1: 6 & 58 \cdot 8 \\ 7: 1 & 42 \cdot 2 \\ 6: 1 & 22 \cdot 6 \\ 1: 7 & 36 \cdot 3 \\ 1: 8 & 54 \cdot 4 \\ \text { I: } 3 & 57 \cdot 1\end{array}$

* Each of the mutants required inositol (inos- $I$ ) in addition to the requirements listed.

$\dagger$ The first number of the ratio corresponds to the first mutant of the heterokaryon.

$\ddagger$ Colony diameter of the heterokaryon in SMA, compared with the growth in SCA after 7 days at $25{ }^{\circ} \mathrm{C}$.

Table 6. Induced alteration in the nuclear ratios and colony diameters of the heterokaryons of Fusarium crown-rot wild-type isolate

\begin{tabular}{|c|c|c|c|c|}
\hline \multirow{3}{*}{$\begin{array}{l}\text { Leucine or } \\
\text { tryptophan } \\
\text { added to } \\
\text { minimal agar } \\
(\mu \mathrm{mol} / \mathrm{ml})\end{array}$} & \multicolumn{4}{|c|}{ Heterokaryons } \\
\hline & \multicolumn{2}{|c|}{ nic- $I+\operatorname{trp}-I$ plus tryptophan } & \multicolumn{2}{|c|}{ nic- $I+$ leu-4 plus leucine } \\
\hline & $\begin{array}{l}\text { Nuclear } \\
\text { ratio }\end{array}$ & $\begin{array}{c}\text { Colony } \\
\text { diameter }(\%)\end{array}$ & $\begin{array}{l}\text { Nuclear } \\
\text { ratio }\end{array}$ & $\begin{array}{c}\text { Colony } \\
\text { diameter }(\%\end{array}$ \\
\hline SMA & I $: 40$ & $40 \cdot 2$ & $\mathrm{I}: 8 \cdot 3$ & $46 \cdot I$ \\
\hline $\mathrm{SMA}+0 . \mathrm{I}$ & I $: 5 \mathrm{I}$ & $42 \cdot 0$ & $I: 4 \cdot 6$ & $47 \cdot 4$ \\
\hline $\mathrm{SMA}+\mathrm{I} \cdot \mathrm{O}$ & $I: 4 \mathrm{I}$ & $4 I \cdot 3$ & $1: 7 \cdot 3$ & $46 \cdot 7$ \\
\hline SMA + IO & I $: 26$ & $55 \cdot 8$ & $I: 4 \cdot 0$ & $48 \cdot 5$ \\
\hline $\mathrm{SMA}+100$ & I: I 3 & $9 I \cdot 6$ & $I: 8 \cdot 7$ & $47 \cdot 2$ \\
\hline SCA & I :39 & $100 \cdot 0$ & I $: 250$ & $100 \cdot 0$ \\
\hline
\end{tabular}

Induced alterations in the conidial ratios and colony diameters of heterokaryons

The conidial ratio of heterokaryons remained constant and was specific to the mutants used to establish the heterokaryons. The conidial ratios of several heterokaryons frequently and reproducibly showed that one spore type greatly outnumbered the other. Heterokaryons were grown on SMA supplemented with increasing concentrations of the growth requirement of the mutant not favoured in the conidial ratio, in an attempt to modify that ratio. In one of two heterokaryons studied, the conidial ratio and growth of the colonies was modified significantly ( $5 \%$ level) by supplementing the SMA. In the other heterokaryon CR inos- $I$ nic- $I \times \mathrm{CR}$ inos- $I$ leu-4), colony growth was modified only slightly (Table 6). 


\section{DISCUSSION}

The synthesis of heterokaryons between races of $F$. oxysporum f.sp. pisi has been reported by Buxton (1956), Tuveson \& Garber (I959, I96I) and Fleischmann (I963); between form species by Garber, Wyttenbach \& Dhillon (I96I); and between species by Singh \& Hoffman (1969). Whether this last report dealt with true species is questionable. The present report is the first of heterokaryon formation between different races of F. oxysporum f.sp. lycopersici. We have demonstrated that heterokaryons can be formed between mutants manifesting different degrees of pathogenicity and between mutants of the pathogenic Fusarium crownrot wild-type (CR) strain and mutants of the non-pathogenic Fusarium crown-rot 'purple variant' (PV). Heterokaryons were easily formed between mutants of the CR isolate using several different mutant combinations.

Cross-feeding tests conducted with several pairs of mutants of the three fungal strains demonstrated that growth due to cross-feeding did not occur with most of the mutants tested.

The finding that some pairs of mutants from the same isolates can form heterokaryons while others cannot, suggests three possible explanations: (I) that some pairs of mutants are unable to complement the reciprocal nutritional requirements; (2) that heterokaryon incompatibility loci are involved; (3) that the strains used are intrinsically incapable of forming heterokaryons for some other reason.

Evidence for hypothesis (I) is as follows: (i) Some heterokaryons grew well on supplemented SMA, but when transferred to SMA the growth was poor. (ii) Most of the presumed heterokaryotic hyphal tips were unable to grow on SMA. However, when hyphal tips were isolated on SCA, spores having both parental requirements were recovered. (iii) The recovery of heterokaryotic hyphal fragments from minced mycelium was increased several times when the fragments were overlaid on SMA supplemented with the growth factor of the minority mutant in the conidial ratio. (iv) In one of the heterokaryons studied (Table I), the colony diameter was increased from 40 to $9 \mathrm{I} \%$ of that on SCA when the heterokaryon was grown on SMA supplemented with the amino acid of the mutant low in the conidial ratio. Therefore, the growth of the heterokaryon was limited by one of the component mutants. (v) The fact that the only heterokaryon studied which had a I: I nuclear ratio (Table I) also exhibited growth most comparable to the wild-type suggests that the nuclear ratio, the growth rate and the reciprocal nutritional complementation of the component mutants of the heterokaryon are intimately related.

Evidence for hypothesis (2), heterokaryon incompatibility, is based on mutants that failed to form heterokaryons in certain combinations but were able to form heterokaryons when mated with other mutants having the same growth requirements. This reaction was observed with intra- and inter-isolate crosses. If such changes in heterokaryon incompatibility lcci result from induced mutations, then a similar type of incompatibility may arise in nature by spontaneous mutation. The existence of such incompatibility mechanism in nature would limit the variation of a fungus by preventing the formation of heterokaryons (Caten, 1972).

No attempt was made to differentiate between these possibilities and an intrinsic inability to form heterokaryons.

Both conidial types were recovered from all of the heterokaryons studied (Table 4), and usually one outnumbered the other. Conidial ratios proved to be characteristic of the particular heterokaryon under study. Determinations made at several different times and from many different isolations always produced similar nuclear ratios. The ratio of the two different nuclei is apparently stabilized at a certain level to provide for optimum growth of 
the heterokaryotic mycelium (Warr \& Roper, 1966). The nuclear ratio in Neurospora crassa heterokaryons appears to be characteristic for particular heterokaryons (Prout et al., I953) and the nuclear proportions remain stable during growth of the heterokaryon (Pittinger \& Atwood, 1956). In species such as $F$. oxysporum, where the conidia are uninucleate, the nuclear ratio is usually obtained by determining the conidial ratio of the heterokaryon after growth on minimal medium. Assuming that the conidial ratio of a heterokaryon represents the true population of nuclei in the mycelium, it should be possible to manipulate the nuclear proportion of a mutant in a heterokaryon by mating it with different mutants that result in different ratios. This technique would provide valuable information for studies of phenotypic expression of individual nuclei in heterokaryons.

Finally, the data taken together argue against the existence of heteroplasmon as an explanation for the segregation of the 'purple variant' and indicate that the 'purple-variant' phenotype and the nutritional requirements are both nuclear. Therefore, the most reasonable explanation for the segregation of the 'purple variant' as a constant proportion of the single conidia is that the 'potential' isolates exist as heterokaryons and that the ratio of 'purplevariant' nuclei to wild-type nuclei is under endogenous control similar to that exerted over the nuclear ratio of different auxotrophic mutants in forced heterokaryons.

These studies were submitted by L.E.S. to the University of California, in partial fulfilment of the requirements for a Ph.D.

\section{REFERENCES}

Buxton, E. W. (1956). Heterokaryosis and parasexual recombination in pathogenic strains of Fusarium oxysporum. Journal of General Microbiology $\mathbf{1 5}_{5}, \mathrm{I} 33-\mathrm{I} 39$.

CATEN, E. C. (1972). Vegetative incompatibility and cytoplasmic infection in fungi. Journal of General Microbiology 72, 22 I-229.

CATEN, C. E. \& Jinks, J. L. (1966). Heterokaryosis: its significance in wild homothallic Ascomycetes and Fungi Imperfecti. Transactions of the British Mycological Society 49, 81-93.

FleischmanN, G. (1963). Studies on the wilt of peas caused by Fusarium oxysporum Schl. F. pisi (linf.) S. \& H., race I. Canadian Journal of Botany 4I, I 564-1 584 .

Garber, E. D., Wyttenbach, E. G. \& Dhillon, T.S. (1961). Genetics of phytopathogenic fungi. V. Heterokaryons involving formae of Fusarium oxysporum. American Journal of Botany 48, 325-329.

Leary, J. V. \& Endo, R. M. (I97I). A Fusarium induced root-rot of staked tomatoes. Phytopathology 6r, A 900.

Pittinger, T. H. \& Atwood, C. K. (1956). Stability of nuclear proportions during growth of Neurospora heterokaryons. Genetics 4r, 227-24I.

Prout, T., Huebschman, C., Levene, H. \& Ryan, F. J. (I953). The proportions of nuclear types in Neurospora heterokaryons as determined by plating conidia. Genetics 38, 518-529.

RAPER, J. R. \& Miles, P. G. (I958). The genetics of Schizophyllum commune. Genetics 43, 532-546.

Sanchez, L. E., Leary, J. V. \& Endo, R. M. (I975). Chemical mutagenesis of Fusarium oxysporum f.sp. lycopersici: non-selected changes in pathogenicity of auxotrophic mutants. Journal of General Microbiology 87, 326-332.

Singh, U. P. \& Hoffman, G. M. (1969). Synthesis of heterokaryons and parasexual reaction in Fusarium species. Archiv für Mikrobiologie 67, 293-305.

SNIDER, P. J. \& RAPER, J. R. (1958). Nuclear migration in the basidiomycete Schizophyllum commune. American Journal of Botany 45, 538-546.

Tuveson, R. W. \& Garber, E. D. (1959). Genetics of phytopathogenic fungi. II. The parasexual cycle of Fusarium oxysporum f, pisi. Botanical Gazette r21, 74-80.

Tuneson, R. W. \& Garber, E. D. (196I). Genetics of phytopathogenic fungi. IV. Experimentally induced alterations in nuclear ratios of heterokaryons of Fusarium oxysporum. f. pisi. Genetics 46, 485-492.

WARR, J. R. \& Roper, J. A. (1966). Resistance to various inhibitors in Aspergillus nidulans. Journal of General Microbiology 40, 278-28I.

Yamamoto, I., Komada, H., KuniYasu, K., Saito, M. \& Ezuka, A. (1974). A new race of Fusarium oxysporum f.sp. lycopersici inducing root rot of tomato. Proceedings of the Kansai Society 16, 17-29. 